\title{
МЕРЫ АДМИНИСТРАТИВНОГО ПРЕСЕЧЕНИЯ И ПРОБЛЕМЫ ИХ РЕАЛИЗАЦИИ В ДЕЯТЕЛЬНОСТИ ПОЛИЦИИ
}

$\mathrm{M}$ еры административного пресечения используются как в интересах общества, государства, так и в интересах самого правонарушителя. Так, помещение правонарушителя, находящегося в общественном месте в сильной степени опьянения, в медицинский вытрезвитель предохраняет его от возможного ограбления, а иногда «при низкой температуре воздуха» предохраняет его от утраты здоровья и замерзания. Целям оказания медицинской помощи служит принудительное лечение. Властное прекращение антиобщественной деятельности позволяет предотвратить действия, события, которые усугубили бы ответственность виновного ${ }^{1}$.

Меры административного пресечения в деятельности сотрудников полиции всегда являются мгновенной реакцией органа административной власти на противоправные действия и характеризуются резким вмешательством в организационную, фризическую и имущественную строну жизни подвластного лица. Как указывает, например, Л.Л. Попов: «...практически невозможно в каждом возможном случае применения мер административного пресечения доказывать правомочность требования, на котором основано принуждение» ${ }^{2}$. В связи с этим, замечает А.В. Серегин, нормы, устанавливающие названные принудительные меры, обращены не к лицам, в отношении которых они применяются, а

\footnotetext{
${ }^{1}$ См.: Фролов В.В. Административное пресечение как мера административно-правового принуждения [Электронный ресурс]. - Томск, $2001 / /$ http://5ballov.qip.ru/ referats/preview/30710 (дата обращения 22.01.2013).

${ }^{2}$ Попов Л.Л. Эффективность административно-правовых санкций. - М., 1976. - С.36.
}

к органам и должностным лицам, их осуществляющим ${ }^{3}$.

Меры административного пресечения связаны с прямым вмешательством в деятельность субъекта, что позволяет в большинстве случаев фактически решить его фризической возможности действовать. Не случайно в группе мер административного пресечения, называемых Федеральным законом от 7 февраля 2011 г. «О полиции» ${ }^{4}$, лишь одна мера - требование прекратить противоправное поведение, лишена свойства материального (физического) воздействия. Арсенал мер административного пресечения, применяемых сотрудниками полиции, весьма разнообразен: от требования прекратить противоправное поведение до применения огнестрельного оружия. По своей сущности это меры психического (угроза применить средства принуждения), материального или физического воздействия, в том числе с использованием технических (специальных) средств и оружия, а также оперативные действия, связанные с личным, организационным или имущественным ограничением, благодаря совершению которых правонарушитель лишается возможности продолжить правонарушение, побуждается к исполнению правовых обязанностей 5 .

\footnotetext{
${ }^{3}$ См.: Серегин A.B. Советский общественный порядок и административно-правовые средства его укрепления. M., 1975. - C.38

${ }^{4}$ См.: Собрание законодательства РФ. - 2011. - № 7. Ст. 900.

5 См.: Фролов В.В. Административное пресечение как мера административно-правового принуждения [Электронный ресурс]. - Томск, 2001 // http://5ballov.qip.ru/ referats/preview/30710 (дата обращения 22.01.2013).
} 
Таким образом, данный признак мер административного пресечения, а именно нарушение при необходимости фризической неприкосновенности граждан, совершающих антиобщественные противоправные деяния, дает возможность отграничить их от карательных санкций. Если перечень последних четко установлен законом, то перечень пресекательных мер, содержащийся в нормативных актах, нельзя считать исчерпывающим. Их использование часто связано с ситуацией необходимой обороны или крайне необходимости, в которой оказались исполнительная власть, ее представители. И вполне возможно, что представитель власти вынужден будет воспользоваться неназванными прямо в законе средствами, например, веревкой, топором, применить меры, которые диктуются экстремальной ситуацией ${ }^{6}$.

При условии их квалифицированного применения меры пресечения способны самостоятельно, вне связи с иными мерами административного принуждения, полностью реализовать заложенную в них правовую цель. В отличие от мер административного пресечения, реализация иных мер административного принуждения, например, административного наказания, требует нередко использования иных принудительных средств, а именно административно-процессуального характера. Меры пресечения во многих случаях применяются непосредственно на основе факта нарушения без издания письменных актов, так как необходимость срочно прервать противоправные действия исключает такую возможность. Юридическим фрактом, влекущим принуждение, здесь является само нарушение, для прекращения которого должностное лицо предпринимает определенные действия (использует резиновою палку, огнестрельное оружие и

\footnotetext{
${ }^{6}$ См.: Кокорев А.Н. Меры административного пресечения применяемые органами внутренних дел: автореф. дис. ... канд. юрид. наук. - М., 2007. - С. 23.
}

т.д.). Но не следует забывать, что они тоже являются правовыми актами исполнительной власти. Таким образом, применение мер административного пресечения связано с отрицательным волеизъявлением конкретного лица и не требует предварительного исследования формы вины, а также наличия вины как обязательного условия их применения ${ }^{7}$.

Для применения мер административного пресечения в деятельности сотрудников полиции важен сам факт противоправного поведения, а не его причины, исследование которых в полной мере возможно лишь в ходе решения вопроса о привлечении лица к юридической ответственности ${ }^{8}$.

Особенность мер административного пресечения заключается в своеобразии проявления объективной связи «неправомерное действие - административное принуждение», которое заключается в одновременном, одномоментном существовании элементов данной системы. В отличие от них реализация, например, таких мер административного принуждения, как административные наказания, характеризуются более или менее значительным периодом времени с момента совершения правонарушения ${ }^{9}$.

Меры административного пресечения имеют небольшой круг субъектов их применения. Притом чем сильнее правоограничение, которое может вызвать та или иная мера административного пресечения, тем уже круг должностных лиц, управомоченных к их применению, и тем выше требования к их профессиональной подготовке. В этой связи представляется верным мнение В.Н. Опарина о том, что

\footnotetext{
${ }^{7}$ См.: Агеенкова Г.Т. Меры административного пресечения: автореф. дис. ... канд. юрид. наук. - М., 1982. - С.8.

${ }^{8}$ См.: Попов Л.Л. Эффективность административно-правовых санкций. - М., 1976. - С.53.

9 См.: Фролов В.В. Административное пресечение как мера административно-правового принуждения [Электронный ресурс]. - Томск, $2001 / /$ http://5ballov.qip.ru/ referats/preview/30710 (дата обращения 22.01.2013).
} 
в основе отнесения того или иного фредерального органа исполнительной власти к правоохранительным (полицейским) органам лежит обязанность пресекать правонарушения путем применения в необходимых случаях мер непосредственного принуждения ${ }^{10}$.

Система мер пресечения чрезвычайно разнообразна. Вследствие этого многими авторами не раз проводилась попытка классификации и систематизации различных мер пресечения в родовые группы.

Д.Н. Бахрах, исходя из цели и образа воздействия, различает общие, специальные и процессуальные меры пресечения ${ }^{11}$. К общим мерам относятся: превентивное задержание, принудительное лечение, административный надзор за лицами, прибывшими из мест лишения свободы, предписание (предостережение), запрещение эксплуатации, приостановление работ и др. Некоторые из них применяются только к гражданам, другие только к коллективным субъектам, а третьи - и к тем, и к другим. Специальные меры пресечения применяются только к гражданам, они нарушают их фризическую неприкосновенность для того, чтобы быстро прекратить противоправное поведение. В их числе средства простого физического воздействия (приемы боевой борьбы, использование служебных собак); воздействие с помощью технических средств (дубинок, наручников и т.д.); использование огнестрельного оружия, боевой техники.

На наш взгляд, предложенная Д.Н. Бахрахом система мер административного пресечения носит несколько неконкретный характер, строится в известном смысле на искусственном соединении разнопорядко-

\footnotetext{
${ }^{10}$ См.: Опарин В.Н. Правовое регулирование и применение мер непосредственного принуждения должностными лицами правоохранительных органов Российской Федерации: автореф. дис. ... канд. юрид. наук. - Омск, 1998. - C.13.

${ }^{11}$ См.: Бахрах Д.Н. Административное право России. M., 2000. - C.452.
}

вых мер воздействия, которые являются самостоятельными административно-правовыми институтами, а не мерами административного пресечения, например, институт «административного надзора за лицами, освобожденными из мест лишения свободы», - это самостоятельная мера административно-предупредительного характера, а не мера административного пресечения ${ }^{12}$.

М.И. Еропкин полагает, что мерами пресечения (применяемыми в целях охраны общественного порядка) являются административное задержание нарушителей общественного порядка, запрещение эксплуатации автомобилей, приостановление работы предприятий при обнаружении нарушений противопожарных правил, применение оружия ${ }^{13}$. Данный перечень мер пресечения также нельзя признать полным ${ }^{14}$.

Процессуальные меры административного пресечения названы в главе 27 КоАП РФ. Особая цель их применения обеспечить нормальный ход производства по делам об административных правонарушениях: не позволить виновному уклониться от ответственности, собрать необходимые доказательства, обеспечить исполнение постановления. К процессуальным мерам относятся: доставление, задержание, привод, личный досмотр вещей, изъятие вещей и документов, отстранение от управления транспортными средствами, его задержание и др. ${ }^{15}$

\footnotetext{
12 См.: Фролов В.В. Административное пресечение как мера административно-правового принуждения [Электронный ресурс]. - Томск, 2001 // http://5ballov.qip.ru/referats/ preview/30710 (дата обращения 22.01.2013).

${ }^{13}$ См.: Еропкин М.И. О классификации мер административного принуждения // Вопросы советского административного права на современном этапе. - М., 1963. - С. 34.

${ }^{14}$ См.: Мягков А.В. Досмотр как мера административного принуждения, применяемая милицией: дис. ... канд. юрид. наук. - Омск, 2004. - С. 11.

15 См.: Гапонов О.Н. Реализация мер обеспечения производства по делам об административных правонарушениях, посягающих на общественный порядок: автореф. дис... канд. юрид. наук. М., 2006. - С. 19.
} 


\section{Полицейское принуждение}

Многообразные меры административного пресечения в своей интерпретации сгруппировали в несколько видов Ю.М. Козлов и Л.Л. Попов. В частности, к ним относятся: меры, применяемые непосредственно к личности правонарушителя (требование прекратить противоправное поведение, непосредственное фризическое воздействие, административное задержание и доставление в орган внутренних дел и др.); меры имущественного характера (изъятие огнестрельного охотничьего ружья, снос самовольно возведенных строений и др.); меры технического характера (запрещение эксплуатации неисправного транспорта, приостановление работы предприятий в виду нарушения правил техники безопасности, правил пожарной безопасности, запрещение или ограничение ремонтностроительных работ на улицах и дорогах, если не соблюдаются требования по обеспечению общественной безопасности и др.); меры фринансового характера (прекращение кредитования, сокращение бюджетного финансирования, отзыв лицензии, дающей право осуществлять фринансовые операции, изъятие (взимание) в доход бюджета сумм, полученных предприятиями, учреждениями и организациями в результате нарушения фринансовой дисциплины, законодательства о ценах, о реализации нестандартной продукции и др.); меры медико-санитарного характера (отстранение от работы инфекционных больных, запрещение эксплуатации предприятий торговли или общественного питания из-за их антисанитарного состояния и др.); меры, связанные с осуществлением лицензионно-разрешительной системы (отказ в выдаче лицензии на тот или иной подлежащий лицензированию вид деятельности, приостановление или аннулирование лицензии и др.); меры специального и исключительного назначения (применение огнестрельного оружия, химических слезоточивых веществ, водометов, резиновых палок, наручников и др. $)^{16}$.

${ }^{16}$ См.: Козлов Ю.М., Попов Л.Л. Административное право Российской Федерации. - М., 2000. - С.304.
Данная внутривидовая классификация четко распределяет в зависимости от целей, характера и объекта воздействия предметную принадлежность каждой меры административного пресечения. Более точной и практичной является классификация мер административного пресечения, приведенная А.П. Кореневым. Исходя из целей, характера и объекта воздействия, их можно подразделить на меры пресечения: применяемые к нарушителю; имущественного характера; технического характера; санитарно-эпидемиологического характера; фринансово-кредитного характера ${ }^{17}$. Вместе с тем стабильная система мер административного пресечения позволила бы выработать наиболее оптимальные приемы их применения, а также способствовать превращению их в еще более оперативный и динамичный инструмент пресечения правонарушений в сфере общественного порядка. Вот почему стабильная система мер административного пресечения так же необходима, как и стабилизация на длительный период системы административных наказаний. Анализ административного законодательства, регламентирующего применение мер административного пресечения, показывает, что наиболее приемлемой могла бы быть система мер административного пресечения в сорере охраны общественного порядка, учитывающая такие фракторы, как: а) степень самостоятельности (автономности) мер административного пресечения; б) методы воздействия, лежащие в их основе; в) характер объектов воздействия; г) характер сореры воздействия, в которой имеет место применение указанных мер ${ }^{18}$.

В соответствии с указанными признаками меры административного пресечения

\footnotetext{
${ }_{17}$ См.: Коренев А.П. Административное право России. M., 1996. - C.196.

18 См.: Фролов В.В. Административное пресечение как мера административно-правового принуждения [Электронный ресурс]. - Томск, $2001 / /$ http://5ballov.qip.ru/ referats/preview/30710 (дата обращения 22.01.2013).
} 
могут быть классифицированы по четырем самостоятельным группам:

- по степени соподчиненности они бывают самостоятельными (официальное требование о прекращении правонарушения, запрещение эксплуатации транспорта) и вспомогательными (административное задержание, задержание имущества, приостановление работы объекта разрешительной системы, применение физической силы, специальных средств и огнестрельного оружия);

- по методам воздействия пресекательные меры применяются в виде средств психического (официальное требование о прекращении правонарушения) и фризического воздействия (доставление, административное задержание, применение фризической силы, специальных средств и огнестрельного оружия);

- по объектам воздействия меры административного пресечения бывают мерами личностного (доставление, административное задержание, ограничение передвижения по территории России иностранных граждан и лиц без гражданства, применение физической силы, специальных средств и огнестрельного оружия), имущественного (задержание имущества, приостановление работы объекта разрешительной системы и др.), санитарноэпидемиологического (отстранение от работы инфекционно больных, ограничение въезда на территории, где введен карантин), фринансово-кредитного характера (приостановление финансовых операций и др.);

- по характеру сореры воздействия меры административного пресечения могут быть объединены в две группы: меры пресечения общего назначения (доставление, административное задержание и др.) и меры специального назначения (применение фризической силы, специальных средств и огнестрельного оружия) ${ }^{19}$.

Возможны и иные классифрикации мер пресечения в сфрере охраны общественного порядка, но предлагаемая классифрикация позволяет, на наш взгляд, глубже понять и уяснить сущность мер административного пресечения и, что самое главное, применять их в соответствии с действующим законодательством и реальной обстановкой.

К мерам пресечения, применяемым к нарушителю общественного порядка, относятся: требование прекратить противоправные и иные действия, препятствующие выполнению функций государственных органов и должностных лиц; непосредственное применение фризической силы, специальных средств и оружия; задержание и доставление; принудительное лечение страдающих заболеваниями, опасными для окружающих; временное отстранение от работы инфекционных больных, а также лиц, находящихся в болезненном и ином состоянии, препятствующем безопасному для окружающих выполнению ими обязанностей.

Рассмотрим каждый из подвидов мер пресечения, применяемых к нарушителю в отдельности.

Уполномоченные должностные лица (сотрудники полиции и др.) имеют право требовать от граждан и должностных лиц прекращения преступления или административного правонарушения, а также действий, препятствующих осуществлению их полномочий, законной деятельности депутатов, кандидатов в депутаты, представителей государственных органов, учреждений и общественных объединений. Сущность этой меры пресечения заключается в указании правонарушителю на немедленное прекращение совершаемых им

\footnotetext{
19 См.: Гапонов О.Н. Реализация мер обеспечения производства по делам об административных правонарушениях: автореф. дис... канд. юрид. наук. М., 2006. - С. 19.
} 
действий. Учитывая особый характер таких мер административного пресечения, как применение огнестрельного оружия, специальных средств и физической силы, необходимо выделить их в группу специальных мер административного пресечения. Такая внутригрупповая классификация весьма значима, так как позволяет более точно отразить правовую природу названных мер. В частности, той ее стороны, что применение специальных мер административного пресечения чаще всего связано с воздействием на фризическую сущность лица, подвергнутого принуждению.

По данному признаку некоторые авторы называют применение фризической силы, специальных средств и оружия мерами непосредственного воздействия ${ }^{20}$. В то же время другие авторы непосредственность воздействия связывают лишь с применением фризической силы ${ }^{21}$. Стоит согласиться с позицией тех авторов, которые считают, что применение физической силы, специальных средств и оружия - меры непосредственного фризического воздействия, так как названные правовые средства, во-первых, применяются немедленно (непосредственно) при обнаружении правонарушения с целью его пресечения, во-вторых, представляют собой воздействие физического свойства и, в-третьих, направлено в большинстве случаев на фризическую сторону объекта воздействия ${ }^{22}$.

Сотрудники полиции и других правоохранительных органов, а также иных государственных органов и уполномоченные на то законом представители негосударственных объединений имеют право применять фризическую силу, в том числе боевые приемы борьбы, для пресечения

\footnotetext{
${ }^{20}$ См.: Серегин А.В. Основания и порядок применения мер административного воздействия. - М., 1974. - С.25.

${ }^{21}$ См.: Алехин А.П., Кармолиикий А.А., Козлов Ю.М. Административное право России. - М., 1997. - С.266.

${ }^{22}$ См.: Князьков А.С. Применение и использование огнестрельного оружия...... дис. ... канд. юрид. наук. - Тюмень, 1998. - С.35-36.
}

преступлений и административных правонарушений, задержания лиц, их совершивших, преодоления противодействия законным требованиям, если ненасильственные способы не обеспечивают выполнение возложенных на них обязанностей.

Сотрудники полиции, и других специальных служб обладают правом применять специальные средства: резиновые палки, слезоточивый газ, наручники, светозвуковые средства отвлекающего воздействия, средства разрушения преград, средства принудительной остановки транспорта, водометы, резиновые пули, бронемашины, специальные окрашивающие средства, служебных собак и др. Перечень специальных средств устанавливается Правительством Российской Федерации.

Специальные средства и интенсивность их применения избираются с учетом складывающейся обстановки, характера правонарушения и личности правонарушителя. При их применении должна сводиться к минимуму возможность причинения вреда здоровью граждан. Запрещается применять специальные средства в отношении женщин с видимыми признаками беременности, лиц с явными признаками инвалидности и малолетних, кроме случаев оказания ими вооруженного сопротивления, совершения группового либо иного нападения, угрожающего жизни и здоровью людей, а также при пресечении незаконных собраний, митингов, уличных шествий и демонстраций ненасильственного характера, которые не нарушают работу транспорта, связи, предприятий, учреждений и организаций.

Главная особенность применения огнестрельного оружия, как указывают многие авторы ${ }^{23}$, состоит в том, что его реализация не связана с пресечением административного правонарушения, а обусловлена необходимостью немедленного

${ }^{23}$ См.: Бахрах Д.Н. Административная ответственность. - M., 1999. - C. 23. 
прекращения таких действий, которые по степени общественной опасности могут быть квалифрицированны как преступные 24 . Следует заметить, что в некоторых случаях обстоятельства, служащие основаниями применения огнестрельного оружия сотрудниками полиции, внешне напоминают административные правонарушения. Так выглядит, например, попытка завладения табельным оружием сотрудника полиции, когда задерживаемое лицо приближается к нему, отказываясь выполнить требования остановиться, либо создание реальной угрозы жизни и здоровью людей, водителем транспортного средства, нарушающим административные правила дорожного движения и др.

Следует отметить, что в данном случае с помощью огнестрельного оружия пресекаются не административные правонарушения, - что принципиально важно, - а такие противоправные действия, которые, благодаря существованию отдельных внешних обстоятельств (например, управление транспортом в состоянии алкогольного опьянения), достигают степени общественной опасности, присущей уголовно-правовому деянию. В ряде случаев, подчеркивают отдельные авторы, при умышленном либо неосторожном нарушении правил движения квалификация противоправного деяния, как преступления и только как проступка, зависит в основном от наступления вредных последствий ${ }^{25}$. «Законодатель, - подчеркивает Д.Н. Бахрах, - не может признавать общественно опасные деяния преступлением либо по тому, что свойства деяния не до конца опознано, либо потому, что достаточно

\footnotetext{
24 См.: Катюргин С.И. Функции советской милиции. - Омск, 1975. - С.95; Каплунов А.И. Применение огнестрельного оружия в системе мер административного принуждения // Совершенствование административноправовой деятельности органов внутренних дел. - М., 1994. - C.46.

${ }^{25}$ См.: Севрюгин B.E. Теоретические проблемы административного проступка: дис. ... д-ра. юрид. наук. - М., 1994. - C.156.
}

применения мер административного принуждения, либо по другим причинам ${ }^{26}$.

Применение огнестрельного оружия в отличие от других мер административного пресечения всегда носит активный характер, в то время как использование фризической силы и специальных средств в некоторых случаях происходит в форме пассивного сопротивления. В частности, специальные средства применяются для принудительной остановки автотранспорта либо для препятствования движения толпы. Сотрудник полиции при применении фризической силы, специальных средств или огнестрельного оружия действует с учетом создавшейся обстановки, характера и степени опасности действий лиц, в отношении которых применяются физическая сила, специальные средства или огнестрельное оружие, характера и силы оказываемого ими сопротивления. При этом сотрудник полиции обязан стремиться к минимизации любого ущерба ${ }^{27}$.

Сотрудник полиции обязан оказать гражданину, получившему телесные повреждения в результате применения фризической силы, специальных средств или огнестрельного оружия первую помощь, а также принять меры по предоставлению ему медицинской помощи в возможно короткий срок. О причинении гражданину телесных повреждений в результате применения сотрудником полиции фризической силы, специальных средств или огнестрельного оружия полиция в возможно короткий срок, но не более 24 часов уведомляет близких родственников или близких лиц гражданина. О каждом случае причинения гражданину ранения либо наступления его смерти в результате применения сотрудником полиции фризической силы, специальных средств или огнестрельно-

\footnotetext{
${ }^{26}$ Бахрах Д.Н. Административная ответственность. - М., 1999. - C.29.

${ }^{27}$ См.: Кокорев А.Н. Меры административного пресечения: автореф. дис. ... канд. юрид. наук. - М., 2007. - С. 10.
} 
го оружия уведомляется прокурор в течение 24 часов. Сотрудник полиции обязан по возможности сохранить без изменения место совершения преступления, административного правонарушения, место происшествия, если в результате применения им физической силы, специальных средств или огнестрельного оружия гражданину причинено ранение либо наступила его смерть.

О каждом случае применения физической силы, в результате которого причинен вред здоровью гражданина или причинен материальный ущерб гражданину либо организации, а также о каждом случае применения специальных средств или огнестрельного оружия сотрудник полиции обязан сообщить непосредственному начальнику либо руководителю ближайшего территориального органа или подразделения полиции и в течение 24 часов с момента их применения представить соответствующий рапорт.

Сотрудник полиции имеет право лично или в составе подразделения (группы) применять фризическую силу, в том числе боевые приемы борьбы, если несиловые способы не обеспечивают выполнения возложенных на полицию обязанностей, в следующих случаях:

- для пресечения преступлений и административных правонарушений;

- для доставления в служебное помещение территориального органа или подразделения полиции, в помещение муниципального органа, в иное служебное помещение лиц, совершивших преступления и административные правонарушения, и задержания этих лиц;

- для преодоления противодействия законным требованиям сотрудника полиции.

Говоря о специальных средствах, то сотрудник полиции имеет право лично или в составе подразделения (группы) применять специальные средства в следующих случаях:
- для отражения нападения на гражданина или сотрудника полиции;

- для пресечения преступления или административного правонарушения;

- для пресечения сопротивления, оказываемого сотруднику полиции;

- для задержания лица, застигнутого при совершении преступления и пытающегося скрыться;

- для задержания лица, если это лицо может оказать вооруженное сопротивление;

- для доставления в полицию, конвоирования и охраны задержанных лиц, лиц, заключенных под стражу, подвергнутых административному наказанию в виде административного ареста, а также в целях пресечения попытки побега, в случае оказания лицом сопротивления сотруднику полиции, причинения вреда окружающим или себе;

- для освобождения насильственно удерживаемых лиц, захваченных зданий, помещений, сооружений, транспортных средств и земельных участков;

- для пресечения массовых беспорядков и иных противоправных действий, нарушающих движение транспорта, работу средств связи и организаций;

- для остановки транспортного средства, водитель которого не выполнил требование сотрудника полиции об остановке;

- для выявления лиц, совершающих или совершивших преступления или административные правонарушения;

- для защиты охраняемых объектов, блокирования движения групп граждан, совершающих противоправные действия. Сотруднику полиции запрещается применять специальные средства:

- в отношении женщин с видимыми признаками беременности, лиц с явными признаками инвалидности и малолетних лиц, за исключением случаев оказания указанными лицами вооруженного сопротивления, совершения группового либо иного нападения, угрожа- 


\section{Полицейская деятельность 6 • 2013}

ющего жизни и здоровью граждан или сотрудника полиции;

- при пресечении незаконных собраний, митингов, демонстраций, шествий и пикетирований ненасильственного характера, которые не нарушают общественный порядок, работу транспорта, средств связи и организаций.

Специальные средства применяются с учетом следующих ограничений:

- не допускается нанесение человеку ударов палкой по голове, шее, ключичной области, животу, половым органам, в область проекции сердца;

- не допускается применение водометов при температуре воздуха ниже нуля градусов Цельсия;

- не допускается применение средств принудительной остановки транспорта в отношении транспортных средств, предназначенных для перевозки пассажиров (при наличии пассажиров), транспортных средств, принадлежащих дипломатическим представительствам и консульским учреждениям иностранных государств, а также в отношении мотоциклов, мотоколясок, мотороллеров и мопедов; на горных дорогах или участках дорог с ограниченной видимостью; на железнодорожных переездах, мостах, путепроводах, эстакадах, в туннелях;

- установка специальных окрашивающих средств на объекте осуществляется с согласия собственника объекта или уполномоченного им лица, при этом сотрудником полиции принимаются меры, исключающие применение указанных средств против случайных лиц.

Применение водометов и бронемашин осуществляется по решению руководителя территориального органа с последующим уведомлением прокурора в течение 24 часов.

Особо следует сказать об огнестрельном оружии. Как отмечается в научной литературе, «...являясь фризическим средством пресечения неправомерных действий, огнестрельное оружие представляет собой такое техническое устройство, результат применения которого, как указывали еще отечественные юристы начала нынешнего века, не может быть учтен заранее» ${ }^{28}$.

Применение оружия может дать непредсказуемые фактические последствия: от легкой раны до смерти лица. И в том, и в другом случае решающую роль могут сыграть случайные фракторы: окружающая обстановка, почва, дорожное покрытие и даже конструктивные особенности табельного оружия, которым оснащена полиция.

Одним из характерных признаков применения огнестрельного оружия является реализация данной меры в сверхэкстремальных, стрессовых условиях. Причем стресс вызывают как сами общественно опасные действия правонарушителя, так и осознание возможности причинения серьезного вреда в результате выстрела, а, кроме того - и боязнь ответственности за причиненный ущерб и невыполнение служебного долга. По мнению авторов, исследовавших особенности психических процессов сотрудников полиции в ситуации действия оружием, данная мера принуждения всегда реализуется в экстремальных условиях и характеризуется особым напряжением психологических сил лица ${ }^{29}$.

Сотрудник полиции имеет право лично или в составе подразделения (группы) применять огнестрельное оружие в следующих случаях:

- для защиты другого лица либо себя от посягательства, если это посягательство сопряжено с насилием, опасным для жизни или здоровья;

- для пресечения попытки завладения огнестрельным оружием, транспорт-

\footnotetext{
${ }^{28}$ Гаген В.А. Учебник административного права. - Ростов н/Д, 1916. - С. 8 // цит. по кн. А.И. Елистратова Административное право РСФСР. - Л., 1925. - С. 78.

${ }^{29}$ См.: Хвастунов А.А., Колюхов В.Г. Применение оружия как экстремальная ситуация деятельности сотрудников органов внутренних дел. - Домодедово, 1994. - С.91.
} 
ным средством полиции, специальной и боевой техникой, состоящими на вооружении (обеспечении) полиции;

- для освобождения заложников;

- для задержания лица, застигнутого при совершении деяния, содержащего признаки тяжкого или особо тяжкого преступления против жизни, здоровья или собственности, и пытающегося скрыться, если иными средствами задержать это лицо не представляется возможным;

- для задержания лица, оказывающего вооруженное сопротивление, а также лица, отказывающегося выполнить законное требование о сдаче находящихся при нем оружия, боеприпасов, взрывчатых веществ, взрывных устройств, ядовитых или радиоактивных веществ;

- для отражения группового или вооруженного нападения на здания, помещения, сооружения и иные объекты государственных и муниципальных органов, общественных объединений, организаций и граждан;

- для пресечения побега из мест содержания под стражей подозреваемых и обвиняемых в совершении преступлений или побега из-под конвоя лиц, задержанных по подозрению в совершении преступления, лиц, в отношении которых применена мера пресечения в виде заключения под стражу, лиц, осужденных к лишению свободы, а также для пресечения попытки насильственного освобождения указанных лиц.
Сотрудник полиции также имеет право применять огнестрельное оружие:

- д для остановки транспортного средства путем его повреждения, если управляющее им лицо отказывается выполнить неоднократные требования сотрудника полиции об остановке и пытается скрыться, создавая угрозу жизни и здоровью граждан;

- для обезвреживания животного, угрожающего жизни и здоровью граждан и (или) сотрудника полиции;

- для разрушения запирающих устройств, элементов и конструкций, препятствующих проникновению в жилые и иные помещения;

- для производства предупредительного выстрела, подачи сигнала тревоги или вызова помощи путем производства выстрела вверх или в ином безопасном направлении.

Запрещается применять огнестрельное оружие с производством выстрела на поражение в отношении женщин, лиц с явными признаками инвалидности, несовершеннолетних, когда их возраст очевиден или известен сотруднику полиции, за исключением случаев оказания указанными лицами вооруженного сопротивления, совершения вооруженного или группового нападения, угрожающего жизни и здоровью граждан или сотрудника полиции. Сотрудник полиции не имеет права применять огнестрельное оружие при значительном скоплении граждан, если в результате его применения могут пострадать случайные лица.

\section{Библиография:}

1. Коренев А.П. Административная деятельность органов внутренних дел. Часть особенная / А.П. Коренев [и др.]. - М.: Щит-М, 2003. - 342 с.

2. Капитонов С.А. Ведущая функция милиции / С.А. Капитонов. - М.: Юриспруденция, 2002. - 160 c.

3. Каплунов А.И. Применение и использование огнестрельного оружия / А.И. Каплунов, С.Ф. Милюков. - СПб.: Юридический центр Пресс, 2003. - 363 с.

4. Костенников М.В. Административная деятельность органов внутренних дел. Особенная часть. / М.В. Костенников, А.В. Куракин. - М.: Щит-М, 2003. - 344 с. 


\section{Полицейская деятельность 6 • 2013}

5. Костенников М.В. Актуальные проблемы административно-правового регулирования / М.В. Костенников, А.В. Куракин. Т. 1. - М.: Маросейка, 2010. - 496 с.

6. Костенников М.В. Административный запрет как средство противодействия коррупции в системе государственной службы / М.В. Костенников, А.В. Куракин. - М.: ЮНИТИ-ДАНА, Закон и право, 2010. - 127 с.

7. 7. Куракин А.В. Актуальные проблемы науки административного права. - М.: Маросейка, 2011. - 573 с.

8. Костенников М.В. Административный финансовый контроль в системе МВД России / М.В. Костенников, А.В. Куракин, В.Н. Кузнецов. - Домодедово: ВИПК МВД России, 2011. - 124 C.

9. Фролов В.В. Административное пресечение как мера административно-правового принуждения [Электронный ресурс]. - Томск, 2001 // http://5ballov.qip.ru/referats/ preview/30710

10. К.А. Кареева-Попелковская Акты реализации мер административного пресечения в деятельности полиции // Административное и муниципальное право. - 2011. - 12. С. $39-48$.

11. Кареева-Попелковская К.А. Меры административного пресечения в деятельности полиции // Административное и муниципальное право. - 2011. - 8. - С. 47 - 51.

12. Куракин А.В. Компетенция полиции в сфере реализации законодательства об административных правонарушениях // NB: Административное право и практика администрирования. - 2013. - 4. - С. 28 - 48. URL: http://www.e-notabene.ru/al/article_8841.html

13. Трегубова Е.В. Административные запреты в сфере осуществления полицейской деятельности // NB: Российское полицейское право. - 2013. - 1. - C. 25 - 44. URL: http:// www.e-notabene.ru/pm/article_718.html

14. Кареева-Попелковская К.А. Институт административного принуждения в системе государственного принуждения и его реализация в деятельности органов внутренних дел // Полицейская деятельность. - 2011. - 6. - С. 46 - 55.

15. Куракин А.В., Костенников М.В. Принципы организации и деятельности российской полиции // NB: Российское полицейское право. - 2013. - 2. - С. 22 - 49. URL: http:// www.e-notabene.ru/pm/article_799.html

\section{References (transliteration):}

1. Korenev A.P. Administrativnaya deyatel'nost' organov vnutrennikh del. Chast' osobennaya / A.P. Korenev [i dr.]. - M.: Shchit-M, 2003. - 342 s.

2. Kapitonov S.A. Vedushchaya funktsiya militsii / S.A. Kapitonov. - M.: Yurisprudentsiya, 2002. - $160 \mathrm{~s}$.

3. Kaplunov A.I. Primenenie i ispol'zovanie ognestrel'nogo oruzhiya / A.I. Kaplunov, S.F. Milyukov. - SPb.: Yuridicheskii tsentr Press, 2003. - 363 s.

4. Kostennikov M.V. Administrativnaya deyatel'nost' organov vnutrennikh del. Osobennaya chast'. / M.V. Kostennikov, A.V. Kurakin. - M.: Shchit-M, 2003. - 344 s.

5. Kostennikov M.V. Aktual'nye problemy administrativno-pravovogo regulirovaniya / M.V. Kostennikov, A.V. Kurakin. T. 1. - M.: Maroseika, 2010. - 496 c.

6. Kostennikov M.V. Administrativnyi zapret kak sredstvo protivodeistviya korruptsii $v$ sisteme gosudarstvennoi sluzhby / M.V. Kostennikov, A.V. Kurakin. - M.: YuNITI-DANA, Zakon i pravo, 2010. - 127 s. 
7. Kurakin A.V. Aktual'nye problemy nauki administrativnogo prava. - M.: Maroseika, 2011. -573 c.

8. Kostennikov M.V. Administrativnyi finansovyi kontrol' v sisteme MVD Rossii / M.V. Kostennikov, A.V. Kurakin, V.N. Kuznetsov. - Domodedovo: VIPK MVD Rossii, 2011. - 124 s.

9. Frolov V.V. Administrativnoe presechenie kak mera administrativno-pravovogo prinuzhdeniya [Elektronnyi resurs]. - Tomsk, 2001 // http://5ballov.qip.ru/referats/preview/30710

10. K.A. Kareeva-Popelkovskaya Akty realizatsii mer administrativnogo presecheniya $v$ deyatel'nosti politsii // Administrativnoe i munitsipal'noe pravo. - 2011. - 12. - C. $39-48$.

11. Kareeva-Popelkovskaya K.A. Mery administrativnogo presecheniya v deyatel'nosti politsii // Administrativnoe i munitsipal'noe pravo. - 2011. - 8. - C. 47 - 51.

12. Kurakin A.V. Kompetentsiya politsii $v$ sfere realizatsii zakonodatel'stva ob administrativnykh pravonarusheniyakh // NB: Administrativnoe pravo i praktika administrirovaniya. - 2013. - 4. - C. 28 - 48. URL: http://www.e-notabene.ru/al/article_8841.html

13. Tregubova E.V. Administrativnye zaprety $v$ sfere osushchestvleniya politseiskoi deyatel'nosti // NB: Rossiiskoe politseiskoe pravo. - 2013. - 1. - C. 25 - 44. URL: http:// www.e-notabene.ru/pm/article_718.html

14. Kareeva-Popelkovskaya K.A. Institut administrativnogo prinuzhdeniya $v$ sisteme gosudarstvennogo prinuzhdeniya i ego realizatsiya $v$ deyatel'nosti organov vnutrennikh del // Politseiskaya deyatel'nost'. - 2011. - 6. - C. 46 - 55.

15. Kurakin A.V., Kostennikov M.V. Printsipy organizatsii i deyatel'nosti rossiiskoi politsii // NB: Rossiiskoe politseiskoe pravo. - 2013. - 2. - C. 22 - 49. URL: http://www.e-notabene.ru/ pm/article_799.html 